Iran Journal of Nursing (IJN)

Vol 32, No. 119, Aug 2019: 64- 75

\title{
The Effect of Breastfeeding Training of Grandmothers on Their Attitude
}

\section{toward Breastfeeding}

\author{
Tayebeh Gharaei ${ }^{1}$, Leila Amiri Farahani ${ }^{2}$, Shima Haghani ${ }^{3}$, \\ Seyedeh Batool Hasanpoor-Azghady ${ }^{4}$
}

\begin{abstract}
Background \& Aim: Breastfeeding has many benefits for both babies and their mothers, including scoring higher on IQ tests as adults and reduced chance of diabetes type 2, high serum lipid levels, and hypertension in adulthood (for the former), and decreased chance of breast and ovarian cancer, reduced postpartum hemorrhage by causing uterine contractions and reduced anemia (for the latter). Attitude toward breastfeeding is one of the strong predictors of breastfeeding intention, initiation, and continuation. A positive attitude toward breastfeeding leads to more belief about the benefits of breastfeeding. In addition, a person's attitude toward this issue has a stronger impact on choosing to breastfeed (as a feeding method), compared to other demographic and social factors. Moreover, attitude toward breastfeeding is the first step toward increased breastfeeding duration and amount and can be affected by maternal, cultural, and environmental factors. Several identification factors affect attitude toward breastfeeding positively, which include high maternal age, high socioeconomic status, high level of education, and the decision to breastfeed. On the other hand, return to work was associated with a negative attitude toward breastfeeding. In addition, family members' beliefs and opinions played an important role in mothers' decision to breastfeed. Meanwhile, grandmothers are the key to success in breastfeeding since they affect mothers' intention to initiate and continue breastfeeding using their knowledge and experience. Evaluation of grandmothers' attitude toward breastfeeding can ensure that feeding with breastmilk is the natural feeding approach. Therefore, the present study aimed to determine the effect of the education of grandmothers on their attitude toward breastfeeding.

Materials and Methods: This was a clinical trial with a pretest-posttest design and a control group, which was performed on 64 maternal grandmothers referred to Amir al Momenin Hospital in Tehran in 2018. Eligible individuals were selected by continuous sampling until the desired number of subjects was achieved. The next stage included the non-random allocation of the participants to the groups. The inclusion criteria were being literate, ability to understand and speak Persian, and gestational age of 31-34 weeks reported for their daughters. The subjects were allocated to two intervention $(n=32)$ and control $(n=32)$ groups weekly. In the intervention group, maternal grandmothers of infants participated in two one-hour breastfeeding training sessions along with their primiparous daughters at gestational ages of 31-34 weeks and 35-37 weeks. However, maternal grandmothers in the control group received no training, and the educational content was provided to these individuals at the end of the training sessions of the intervention group. In this study, the Iowa Infant Feeding Attitude Scale was completed by all participants before and after education, which evaluates attitude toward different feeding approaches in a valid and reliable manner. The items are scored based on a five-point Likert scale from one (completely disagree) to five (completely agree), and the score range was 17-85. In this regard, a higher score was indicative of a positive attitude toward breastfeeding. In addition, data analysis was carried out using descriptive and inferential statistics.
\end{abstract}

\footnotetext{
1. MS Student in Midwifery, School of Nursing and Midwifery, Iran University of Medical Sciences, Tehran, Iran

2. Assistant Professor, Nursing Care Research Center (NCRC), Department of Reproductive Health and Midwifery, School of Nursing and Midwifery, Iran University of Medical Sciences, Tehran, Iran (Corresponding author) Tel: +98.2143651139 Email: amirifarahani.l@iums.ac.ir

3. MS. in Biostatistics, Nursing Care Research Center, Iran University of Medical Sciences, Tehran, Iran

${ }^{4}$. Assistant Professor, Nursing Care Research Center (NCRC), Department of Reproductive Health and Midwifery, 
Results: In this study, there was no significant difference between the two groups after the statistical analysis of the participants in terms of demographic characteristics. All grandmothers had breastfeeding experience, and, according to the independent t-test results, there was no significant difference between the groups regarding the mean score of the attitude toward breastfeeding before the intervention $(\mathrm{P}=0.24)$. Immediately after the intervention, however, we detected a significant difference between the groups in this regard $(\mathrm{P}<0.001)$, in a way that the mean score of the intervention group was higher, compared to the control group. Paired t-test also showed that the mean score of breastfeeding attitude of mothers in the intervention and control groups was significantly higher immediately after the intervention, compared to the beginning of the study $(\mathrm{P}<0.05)$. In addition, the mean changes in the control and intervention groups were 0.46 and 12.5, respectively. Moreover, the results were indicative of a higher increase in the score of the intervention group, compared to the control group ( $\mathrm{P}<0.001)$. In other words, the education of grandmothers significantly improved their attitude toward breastfeeding in the intervention group.

Conclusion: According to the results of the present study, raising grandmothers' knowledge of breastfeeding led to an improvement in their attitude toward breastfeeding. In addition, grandmothers' attitude toward breastfeeding more increased in the intervention group immediately after the intervention, compared to the control group. During the training sessions, grandmothers had the chance to share information and experiences and exchange opinions, and ask questions to more effectively understand the topic. After the intervention, some of the participants concluded that they have had false beliefs about breastfeeding, changing their opinions based on the facts presented by the researcher during the training sessions. According to the results, the prenatal breastfeeding training program had a positive effect on mothers' and grandmothers' attitudes toward breastfeeding immediately and one week after the intervention. Grandmothers have little information about breastfeeding, and some of them have a negative attitude toward breastfeeding or have misconceptions about it. Therefore, it is recommended that breastfeeding training classes be held for these individuals to correct these beliefs. The topics presented to the participants in the intervention group included breastfeeding, breastfeeding misconceptions and correction of these beliefs, which increased the mean score of attitude towards breast milk in the grandmothers of the intervention group, compared to the control group. In addition, maternal grandmothers' breastfeeding experience was a predictor of their positive attitude toward breastfeeding. Attitudes toward continued breastfeeding depend on family support, and grandmothers are one of the most important sources of maternal support. Grandmothers' participation in prenatal and postpartum breastfeeding training sessions can encourage mothers to breastfeed and correct their breastfeeding attitudes and misconceptions, and create a positive attitude toward breastfeeding and continued breastfeeding for up to two years. The main goal of breastfeeding training for grandmothers is not only to increase their knowledge and information but also to improve their attitude towards breastfeeding.

Keywords: Breastfeeding Training, Grandmother, Attitude and Breastfeeding

\section{Conflict of Interest: No}

How to Cite: Gharaei T, Amiri Farahani L, Haghani SH, Hasanpoor-Azghady SB. The Effect of the Education of Grandmothers on Their Attitude toward Breastfeeding. Iran Journal of Nursing. 2019; 32(119):64-75.

Received: 15 May 2019

Accepted: 15 Aug 2019 


\title{
تأثير آموزش مادربزرىها بر نكرش آنها نسبت به شيردهى
}

\author{
طيبه قرايى'، ليلا اميرى فراهانى '، شيما حقانى '، سيده بتول حسن يور ازغدى
}

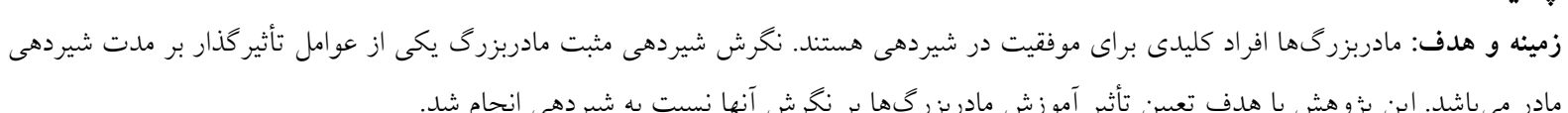

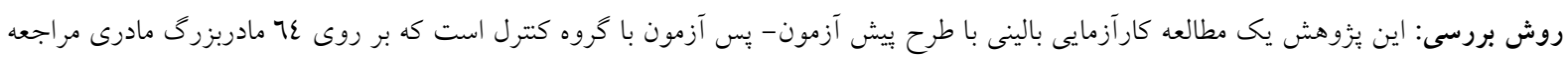

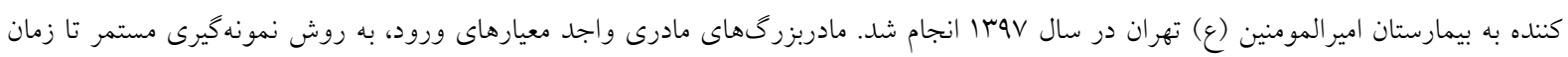

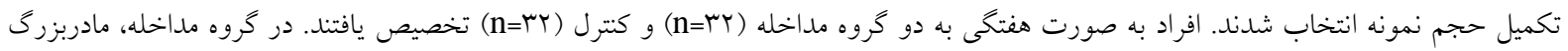

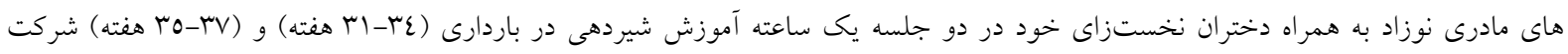

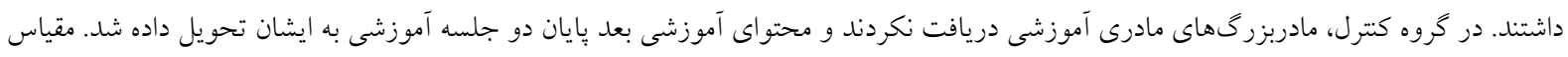

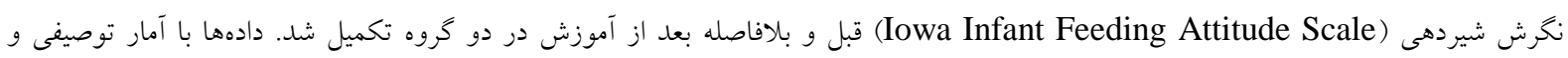
استنباطى تحليل شدند. يافتها: آزمون آمارى تى مستقل، تفاوت آمارى معنى دارى در ميانخين نمره نخرش شيردهى در زمان قبل مداخله بين دو گروه كتترل و مداخله نشان

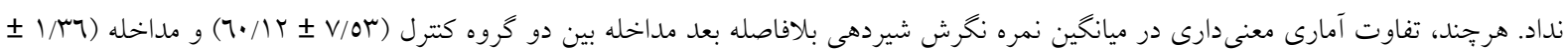

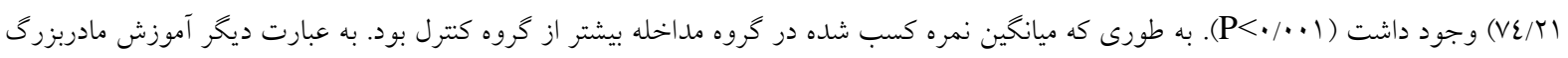

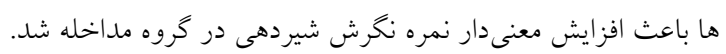

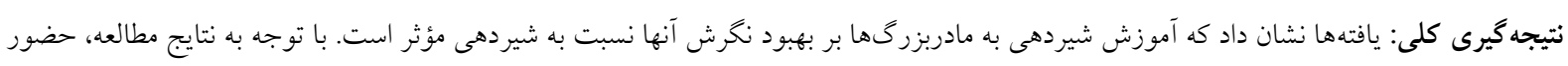

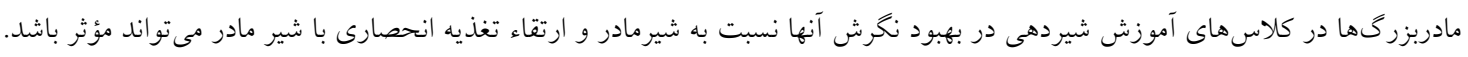

\author{
كليد وازهها: آموزش شيردهى، مادربزرگ، نخرش و شيردهى. \\ تعارض منافع: ندارد \\ تاريخ دريافت: \\ تاريخ بذيرش: ع
}

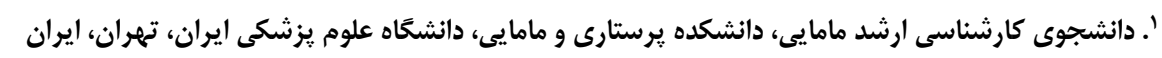

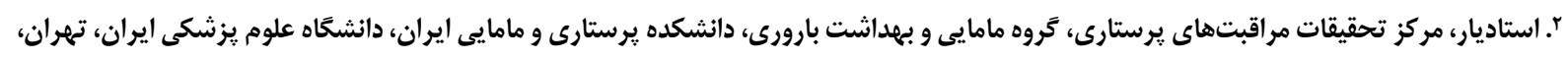
:E-mail :amirifarahani.I@iums.ac.ir

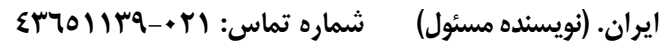

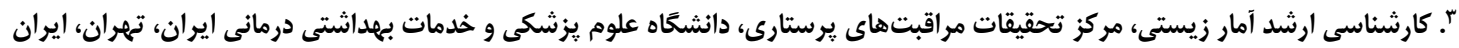

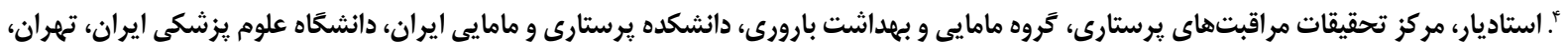


اين نخرش كه شيردهى دردناك و ناراحت كننده است يا

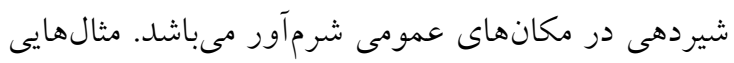

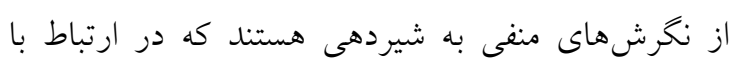

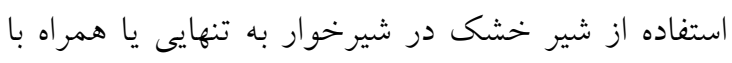
شير مادر هستند (1). به نظر مىرسد كه نخرش نسبت به شيردهى، تحت تأثير

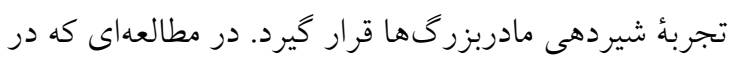

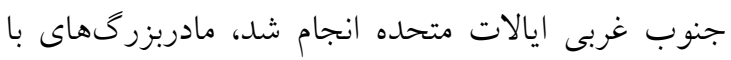

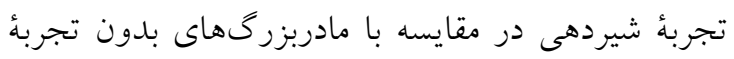

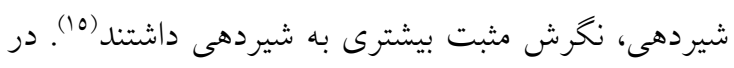

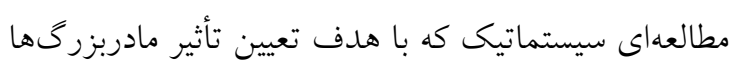

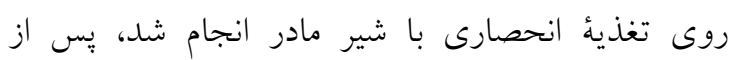

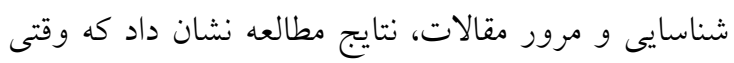

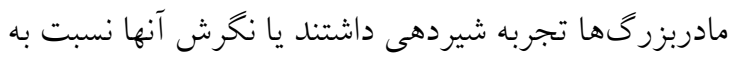
شيردهى مثبت بود، اين مسأله اثر مثبت معنى دارى بر تداوم

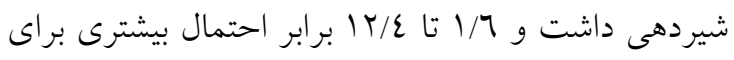
تغذئ انحصارى با شير مادر وجود داشت. اخر مادربزرى

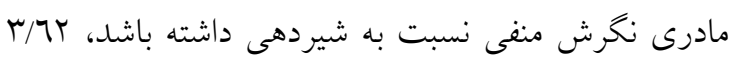

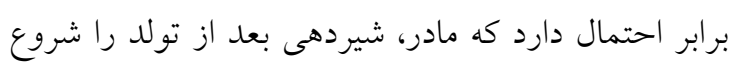

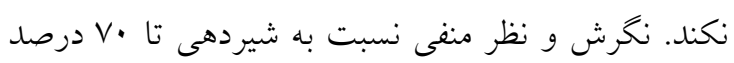

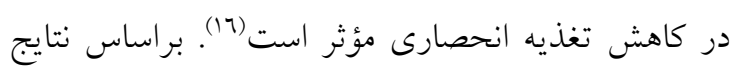

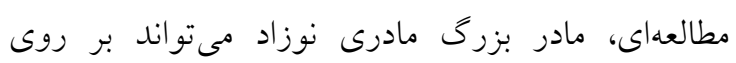

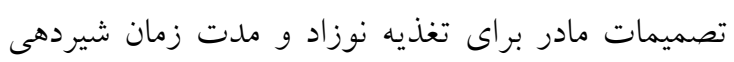
تأثير بخذارد ايجاد نخرش مثبت به تغذيه با شير مادر از اهداف آموزش بارد

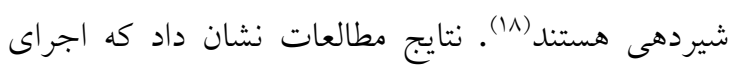

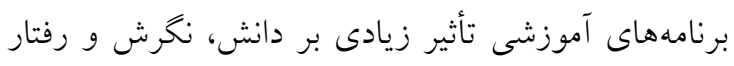

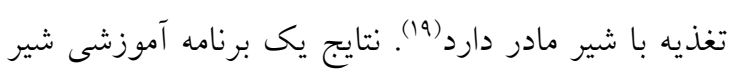

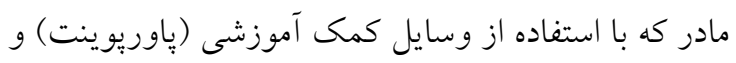

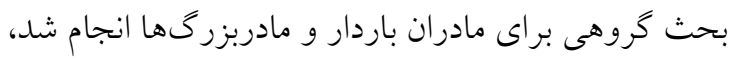

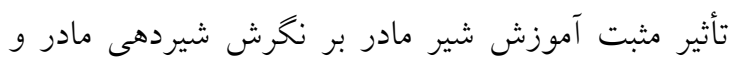
مادربزرگ بلافاصله و يكى هفته بعد مداخله را نشان داد (r.).

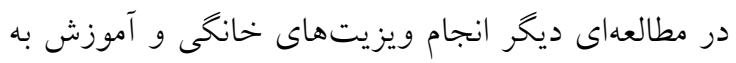

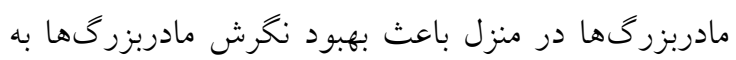

مقدمه

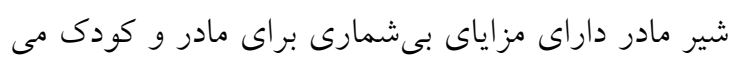

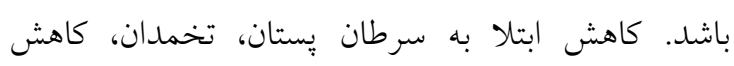

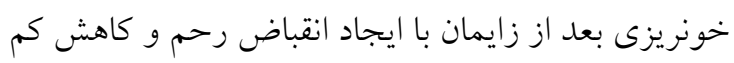

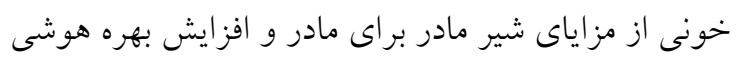

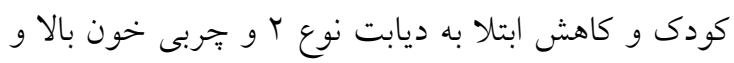

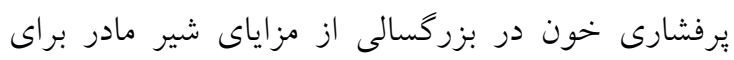
كودى مى باشد (1). يكى از عو املى كه قصد، شروع و ادامه تغذيه با شير مادر

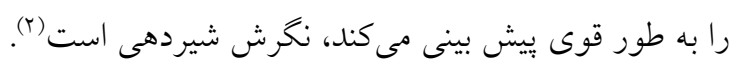

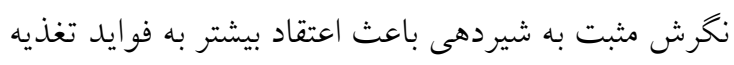

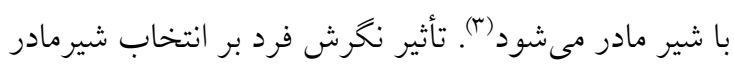

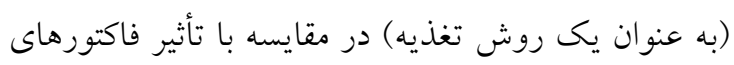

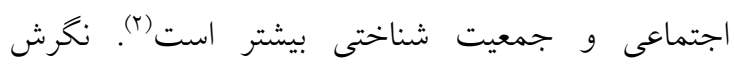

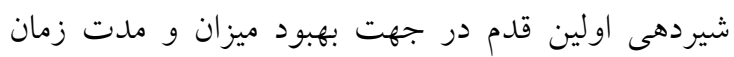

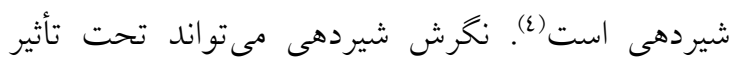
عوامل مادرى، فرهنكى و محيطى قرار خيرد (0.7).

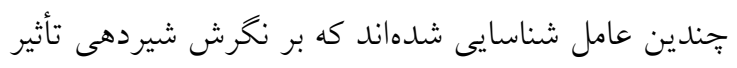

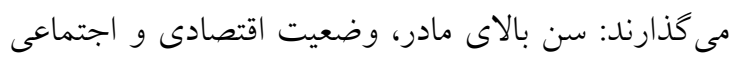

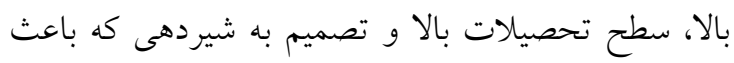

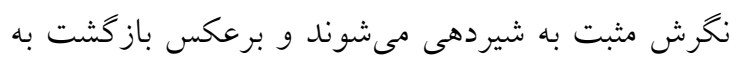

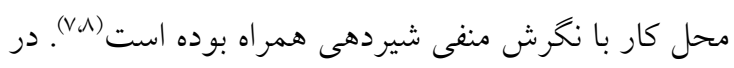

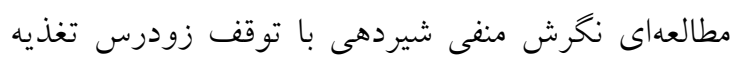

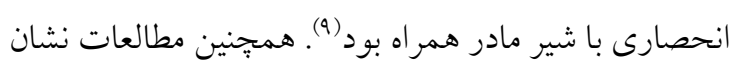

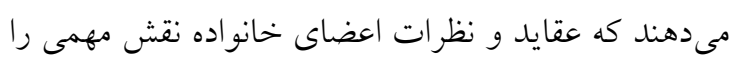

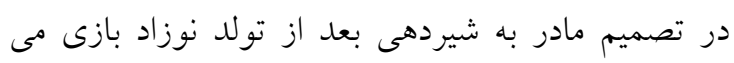

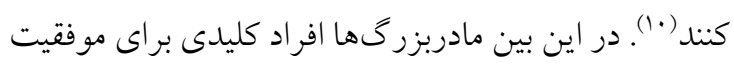

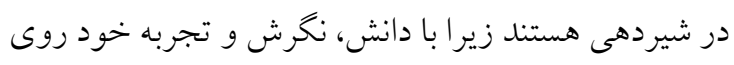

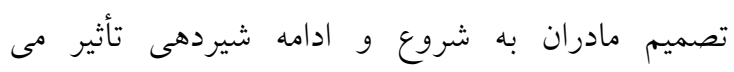

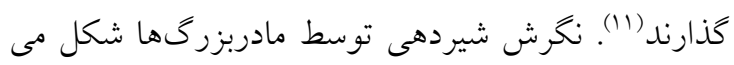

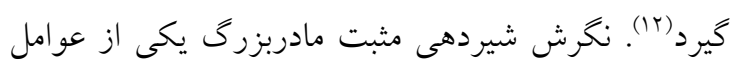

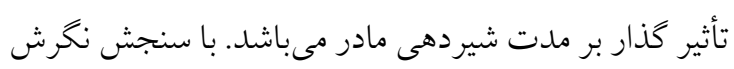

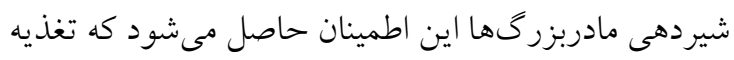
با شير مادر به عنوان روش طبيعى تغذيه نوزاد مىباشد (rامل.) 
مطالعه را مادربزرگهاى مادرى كه به همراه دختران

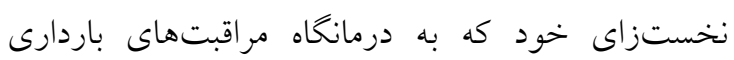

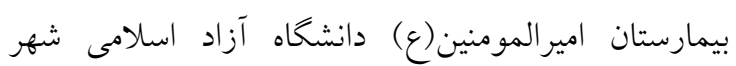

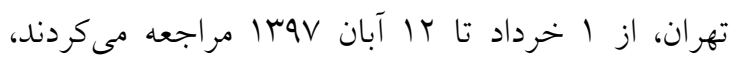
تشكيل دادند. نمونه كيرى به شكل مستمر از ميان افراد واجد شرايط مطالعه تا تكميل حجم نمونه انجام كرفت دئ. تخصيص نمونهها در گروهها به صورت غيرتصادفى انجام

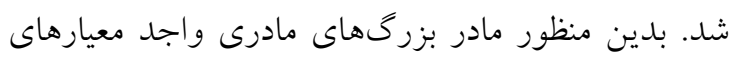

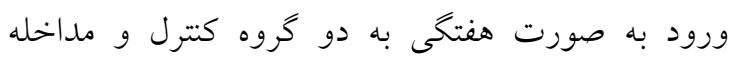
تخصيص يافتند ( يك هفته گروه كنترل و يك هفته كروه

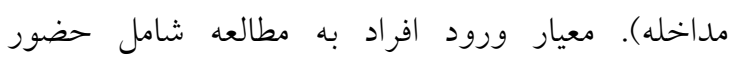

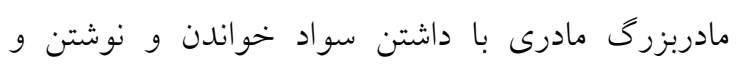

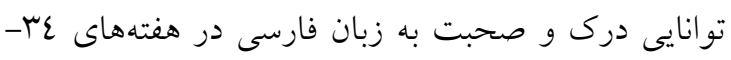

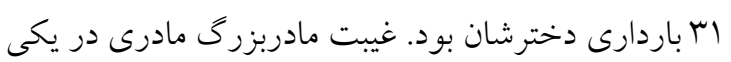

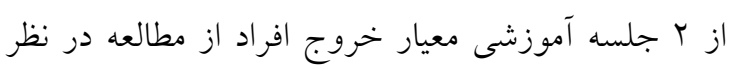
كرفته شد. در گروه مداخله، هر مادربزرى مادرى به همر اه دختر خود

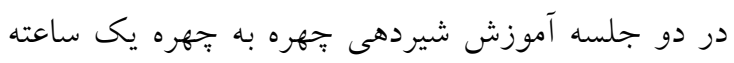
كه در دوران باردارى برگزار شد شركت كرد و از آنان

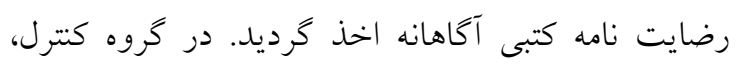

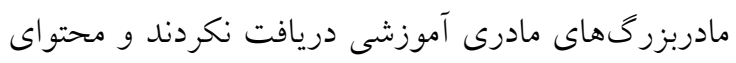

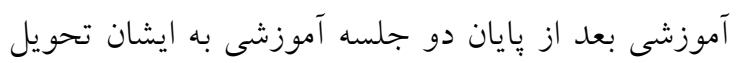

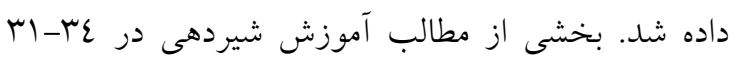

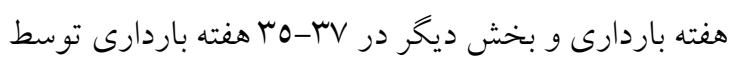

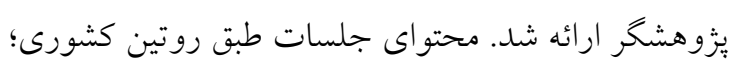
بر اساس راهنماى يايش بيمارستانهاى دوستدار كودى

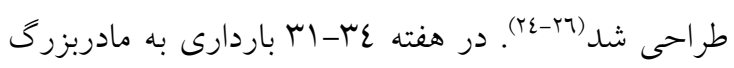
هاى مادرى در گروه مداخله، بخشى از مطالب شيردهى درباره مزاياى شير مادر، اهميت تغذية انحصارى، علايم سيرى وگرسنكى نوزاد، شيردهى بر طبق ميل و تقاضا،

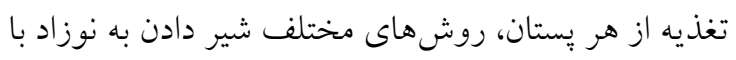

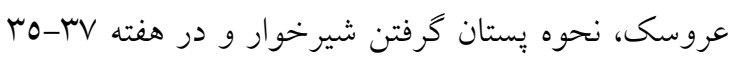

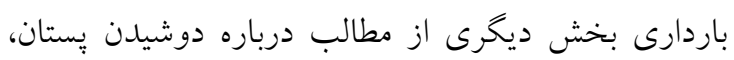

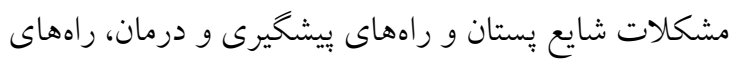

شيردهى شد (YI). مطالعات نشان داد كه اجراى يكى برنامه

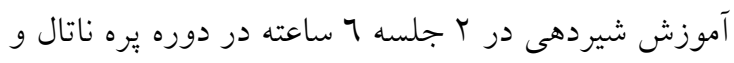
تأثير آن بر نخرش شيردهى مادربزرخ شهاى مادرى در خروه

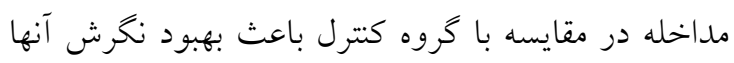
نسبت به شيردهى شده است (11).

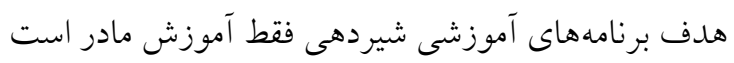

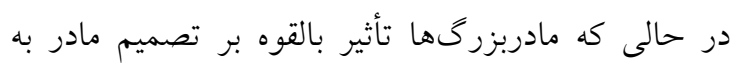

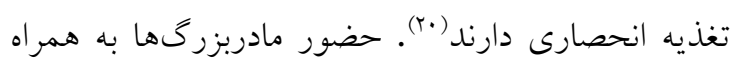
دخترانشان در مراقبتهاى دوران باردارى و در نتيجها

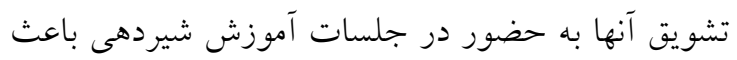
نكرش مثبت مادربزركها به شيردهى مى شود (rا). نتايج

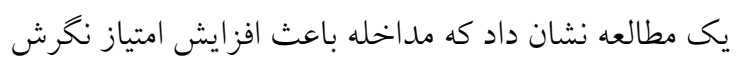
مادربزرخ به شير مادر مىشود (11). در يك مطالعه ديخر نيز

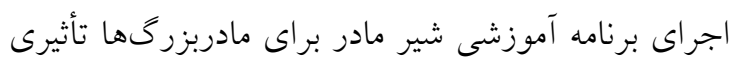
بر نخرش آنها نسبت به شيردهى نداشت أشير مادر براي مادربز

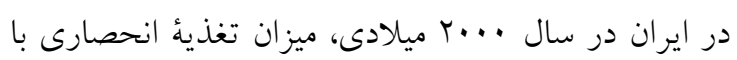

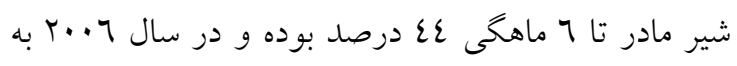

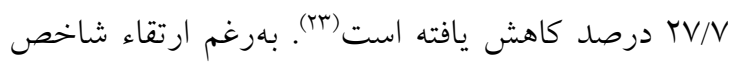

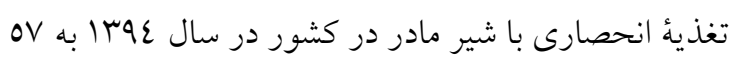

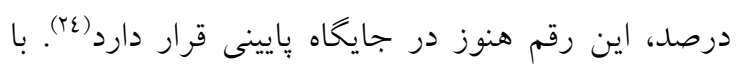

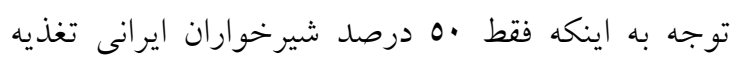

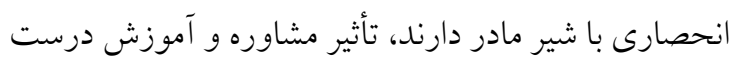

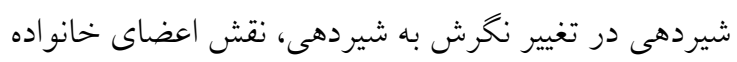

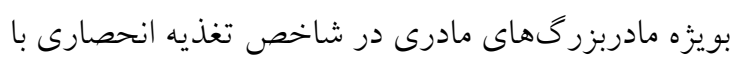

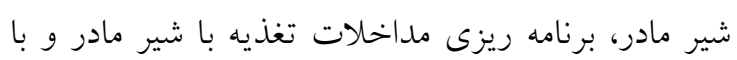

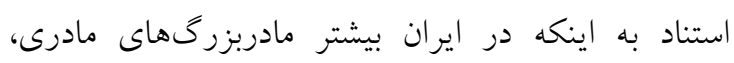

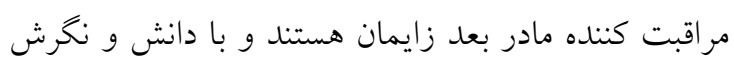
شيردهى بر تصميم مادران به شروع و ادامه شيردهى تأثير

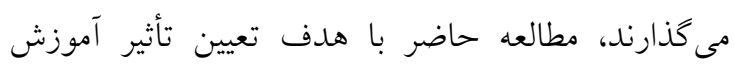
شيردهى مادربزرگها بر نحرش شيردهى آنها طراحى گرديد.

\section{روش بررسى}

اين مطالعه از نوع كارآزمايى بالينى با طرح بيش آزمون-

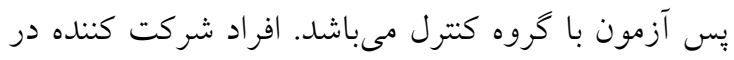


نمونه لازم ^^ نفر در هر گروه بدست آمد كه با احتساب

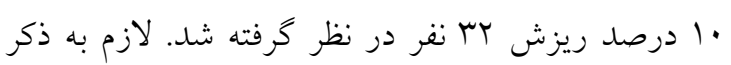

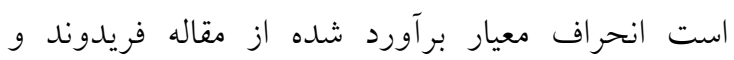

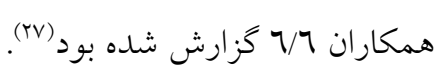

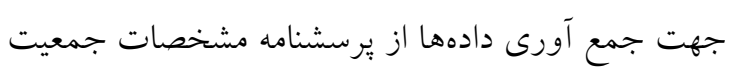
شناختى، مقياس نغرش شيردهى ( Iowa Infant ) (Feeding Attitude Scale جمعيت شناختى شامل مشخصات فردى مادربزرى مادرى نوزاد (سن، تحصيلات، شغل، تجربه شيردهى مادربزر گهنها،

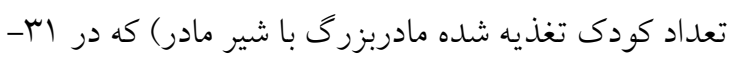

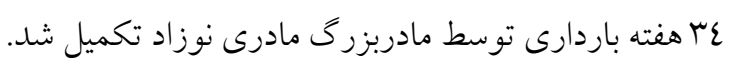

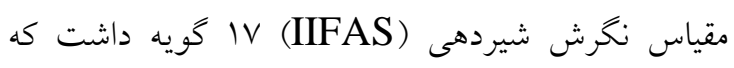

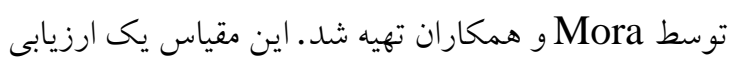

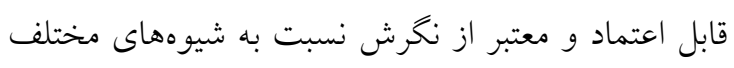

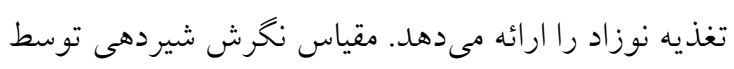

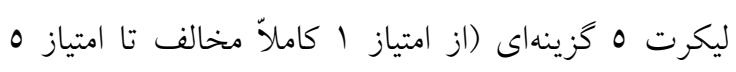

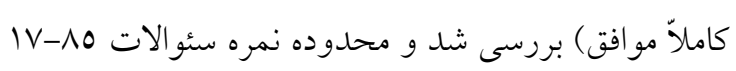

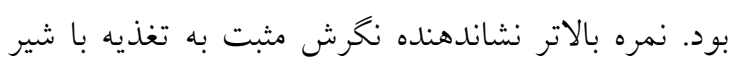

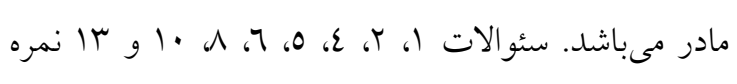
بندى معكوس داشتند و از روايى و وِيايايى مناسبى

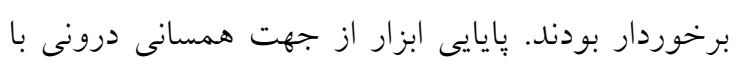

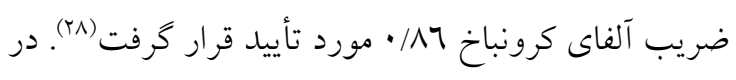
مطالعه حاضر از نسخه فارسى مقياس كوتاه نخرش

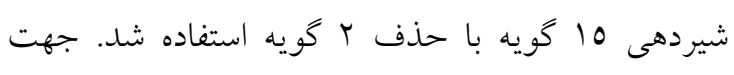
تعيين روايى نسخه فارسى مقياس نخرش شيردهي

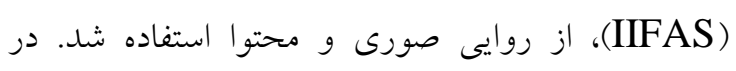

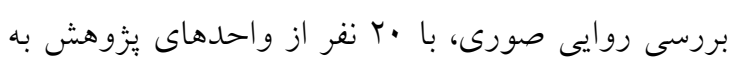

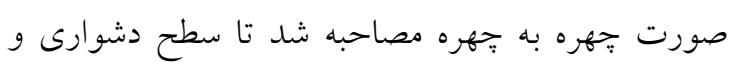

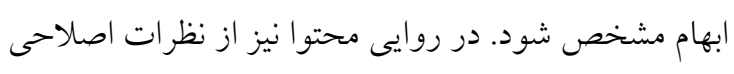

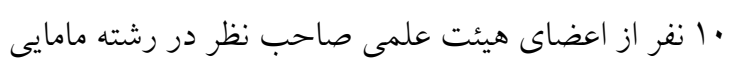

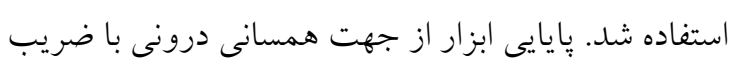

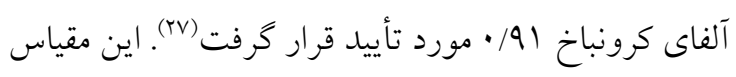
در زمانهاى قبل و بلافاصله بعد از مداخله (يايان جلسه دوم) تكميل شد.
تشخيص كافى بودن شير مادر، حمايت از مادر در شيردهى،

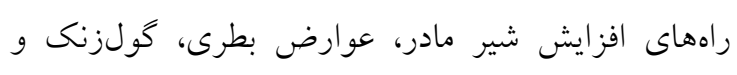

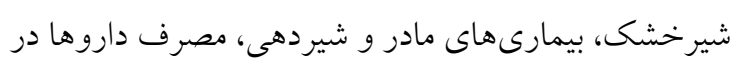

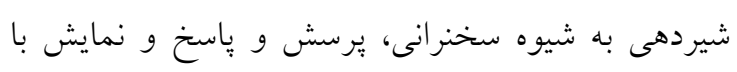
عروسك آموزش داده شد. در هفته عَr-اب باردارى بخشى از مطالب باوند باورهاى

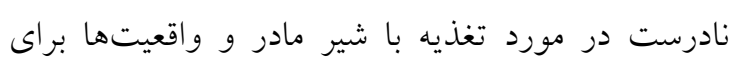
مادربزرى مادرى شامل دور ريختن آغوز به دليل ايجاد

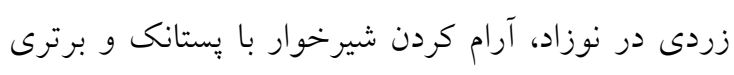

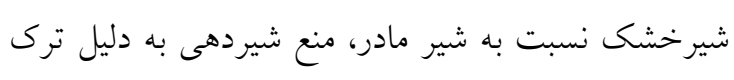

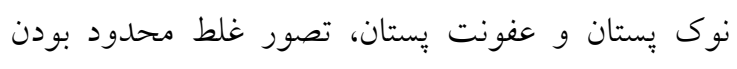

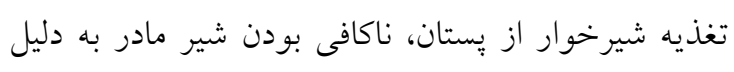

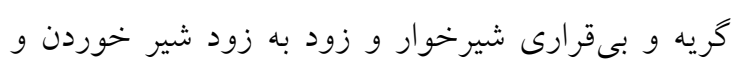
بيدارشدن وى در شب، رقيق و آبكى بودن شير بعضى از

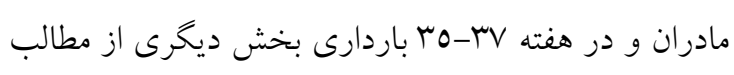
شامل قابل نخهدارى نبودن شير دوشيده شده مادر، دادن

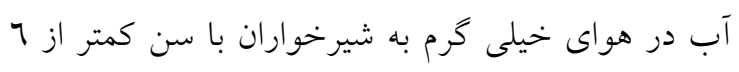

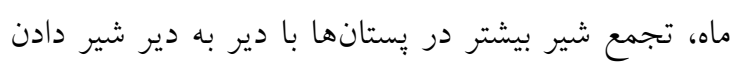

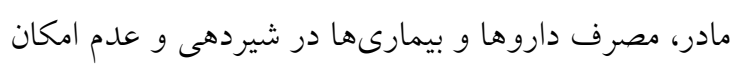
تداوم شيردهى در صورت شاغل بودن مادر يا بيمارى

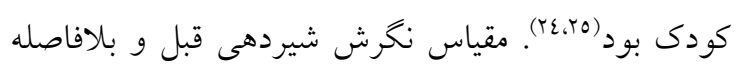

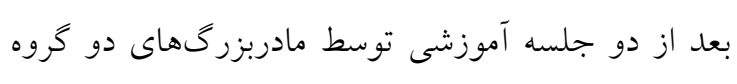
تكميل شد. در يايان هر جلسه به سئوالات آنان نيز ياسخ داده شد و به

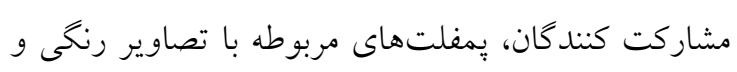

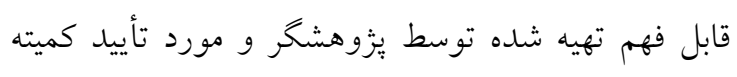

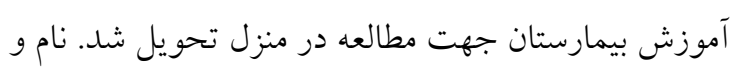

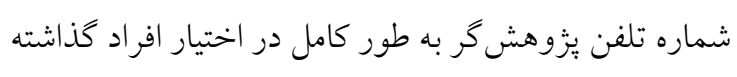

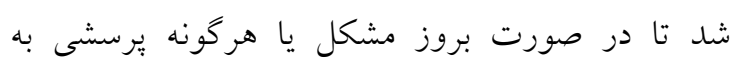
ئزوهش گر اطلاع دهند. براى تعيين حجم نمونه لازم در سطح معنى دارى 0 •٪ و و و

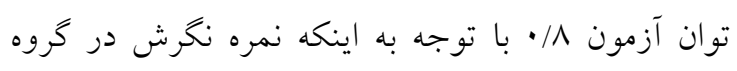

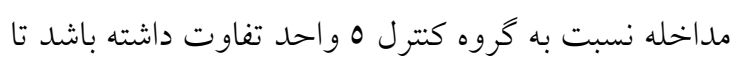
اين اختلاف از نظر آمارى معنىدار باشد حداقد 
مطالعه كاملاً از روند مطالعه مطلع شدند و قبل مطالعه فرم

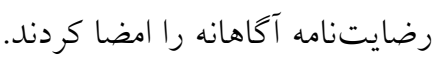

\section{يافتهها}

در اين مطالعه •V مادربزرگ به شرح زير شركت كردند:

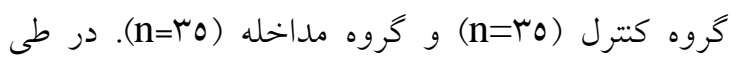

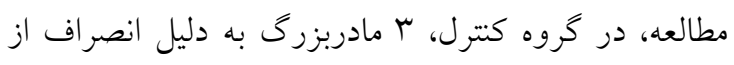

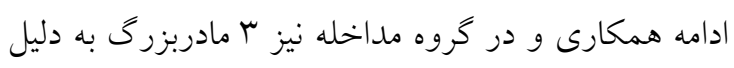

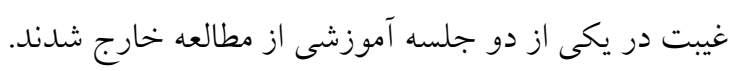
در نهايت، اطلاعات عح مادربزرگ (بس نفر در هر كروه) مورد بررسى قرار گرفتند (تصوير شماره ()).
براى بررسى همخنى متغيرهاى جمعيت شناختى در دو

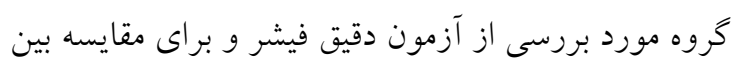

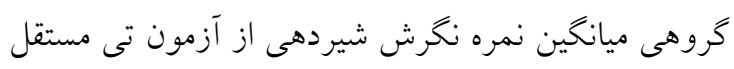

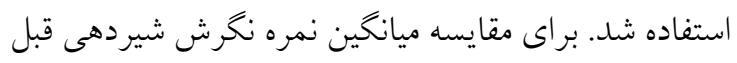

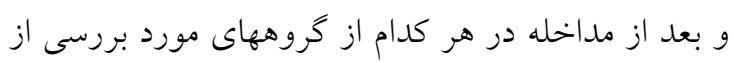

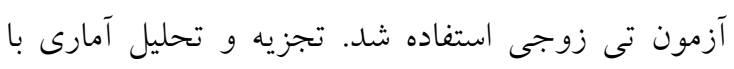

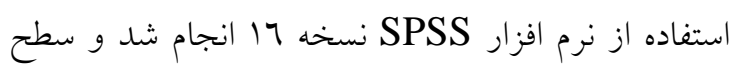

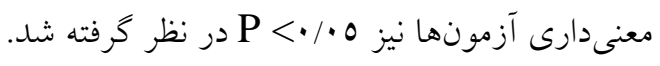

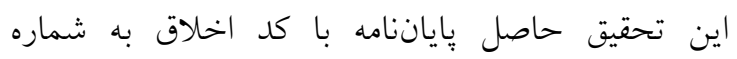
IR.IUMS.REC 1396.9511373007 در مركز ثبت كار آزمايى بالينى ايران با كد كار آزمايى بالينى

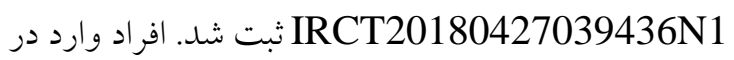

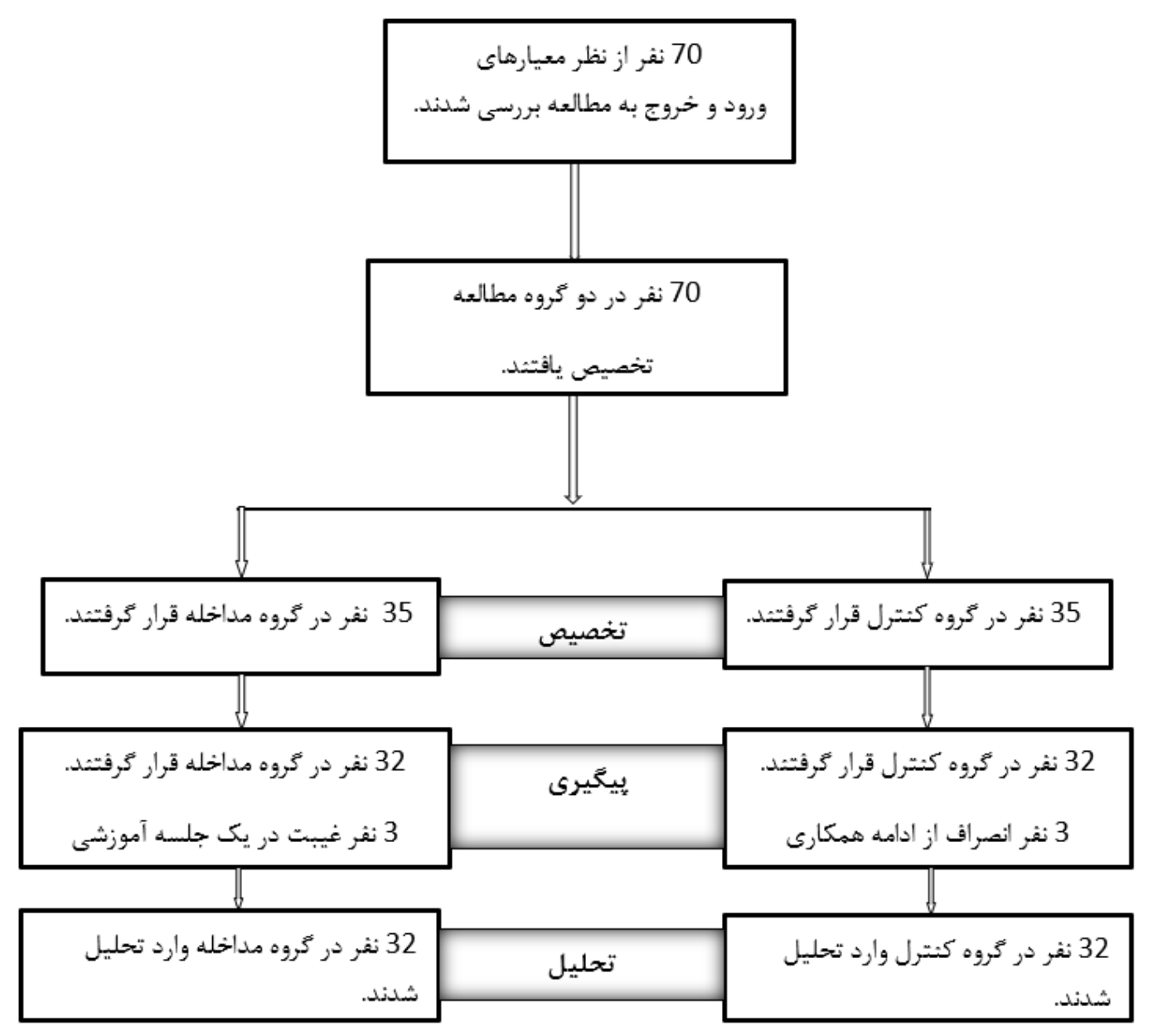

تصوير شماره ا: نحوه تخصيص شركت كنندَان به دو كَروه كنترل و مداخله 


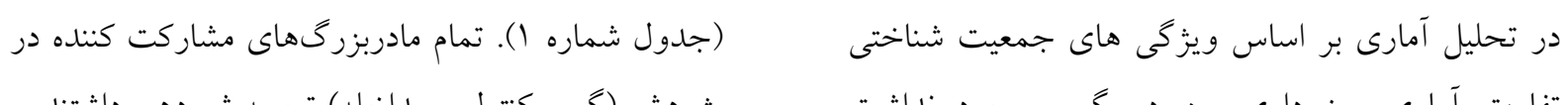
تفاوت آمارى معنى دارى بين دو كروه وجود نداشت يزوهش (كروه كنترل و مداخله) تجربه شيردهى داشتند.

جدول شماره (: ويزَّى هاى دموكَرافيك شركت كنندًَان مطالعه

\begin{tabular}{|c|c|c|c|}
\hline \multirow[t]{2}{*}{ آزمون آمارى } & \multicolumn{2}{|c|}{ كروهها } & \multirow[b]{2}{*}{ 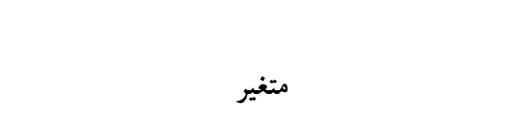 } \\
\hline & مداخله ( & كنترل (n=rr) & \\
\hline تى مستقل & $(\Lambda / 19) \varepsilon \wedge / 9 r$ & $(0 / 7 V) \sum 9 / T_{0}$ & سن مادربزر گها (سال)، ميانخين (انحراف معيار) \\
\hline $\mathrm{t}=\cdot / \mathrm{lVV} \quad \mathrm{df}=\mathrm{rr}$ & & & \\
\hline \multicolumn{4}{|l|}{$\mathrm{P}=\cdot / \wedge \uparrow$} \\
\hline تى مستقل & $(1 / 79) r / 09$ & $(T / / \Gamma) \varepsilon / \varepsilon \cdot$ & تعداد زايمان مادربزرگها \\
\hline $\mathrm{t}=\mathrm{l} / \mathrm{A} \mathrm{df}=\pi \mathrm{r}$ & & & \\
\hline \multicolumn{4}{|l|}{$\mathrm{P}=\cdot / \cdot \mathrm{VI}$} \\
\hline دقيق فيشر & & & اشتغال مادربزرگ، تعداد (درصد) \\
\hline \multirow[t]{2}{*}{$\mathrm{P}=\cdot / 999$} & $(97 / 9)+1$ & (1, ( ) & خانهدار \\
\hline & $(r / 1) 1$ & $(\cdot) \cdot$ & شاغل \\
\hline دقيق فيشر & & & سطح تحصيلات مادربزرگ، تعداد (درصد) \\
\hline \multirow[t]{4}{*}{$\mathrm{P}=\cdot / T 11$} & $(T / Y) Y$ & $\left(Y_{0}\right) \wedge$ & 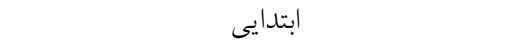 \\
\hline & $(07 / \Gamma) \backslash \Lambda$ & $\left(\sum \tau / 9\right) 10$ & 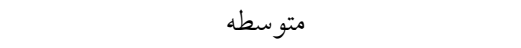 \\
\hline & $\left(Y_{0}\right) \wedge$ & $(Y \backslash / 9) \vee$ & ديبلم \\
\hline & $(1 Y / 0) \varepsilon$ & $(T / r) r$ & دانشخاهى \\
\hline
\end{tabular}

و همجنين در گروه كنترل بلافاصله بعل به طور معنى دارى بالاتر از شروع مطالعه بود (0) (P P). ميانخين تغييرات

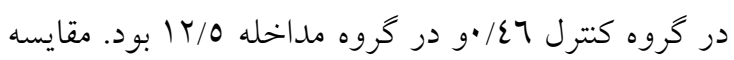
تغييرات نمره نخرش نشاندهنده آن بود كه افزايش نمره در

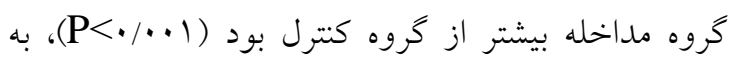
عبارت ديخر آموزش مادربزرگها باعث افزايش معنىدار نمره نخرش شيردهى در گروه مداخله شد (جدول شماره

(r
بر اساس نتيجه آزمون تى مستقل تفاوت آمارى معنى دارى در ميانخين نمره نخرش شيردهى در زمان قبل از مداخله

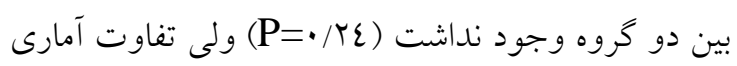
معنى دارى در ميانخين نمره نخرش شيردهى بلافاصله بعد

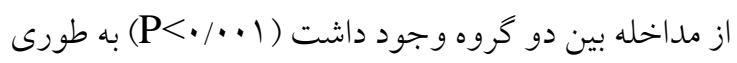
كه ميانخين نمره كسب شده در گروه مداخله بيشتر از گروه كنترل بود. همجنين مقايسه تى زوجى نشاندهنده آن بود كه ميانخين نمره نخرش شيردهى مادران در كروه مداخله

جدول شماره ז: مقايسه ميانگَين نمره نغَرش شيردهى در تروههاى مورد بر رسى در زمانهاى قبل و بلافاصله بعد مداخله

\begin{tabular}{|c|c|c|c|c|c|c|c|c|c|}
\hline \multirow{2}{*}{ نتايج آزمون تى } & \multicolumn{4}{|c|}{ مداخله } & \multicolumn{4}{|c|}{ كترل } & \multirow{2}{*}{ نمره نخرش شرودهرهي } \\
\hline & انحر اف معيار & ميانخين & بيشينه & كمينه & انحر اف معيار & ميانخين & بيشينه & كمينه & \\
\hline $\begin{array}{l}\mathrm{t}=\mathrm{I} / \mathrm{V} \\
\mathrm{df}=\mathrm{Tr}\end{array}$ & $7 / \varepsilon 1$ & $71 / 21$ & $v r$ & 0. & $V / 7 r$ & $09 / 70$ & 75 & 37 & قبل مداخله \\
\hline $\mathbf{P}=\cdot / Y \varepsilon$ & & & & & & & & & \\
\hline $\begin{array}{l}\mathrm{t}=1 \cdot / \varepsilon \\
\mathrm{df}=\pi \mathrm{r}\end{array}$ & 1/אר & $V \varepsilon / T I$ & vo & vi & V/or & $7 \cdot / 1 Y$ & 75 & 37 & بلافاصله بعد مداخله \\
\hline $\mathbf{P}<\cdot / \cdots+1$ & & & & & & & & & \\
\hline
\end{tabular}




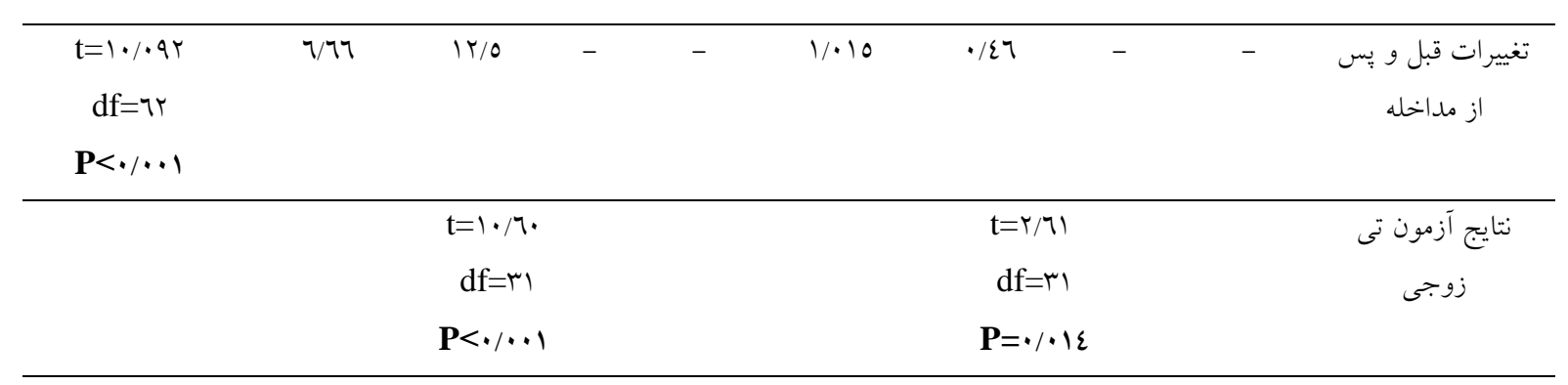

همجنين Bootsri and Taneepanichskul با اجراى

يك برنامه آموزش شيردهى در Y جلسه 7 ساعته در دوره

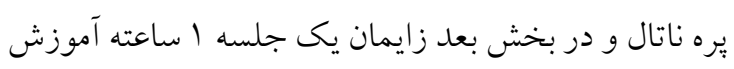

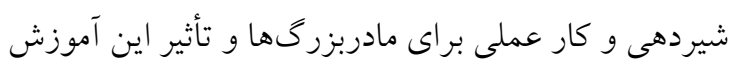

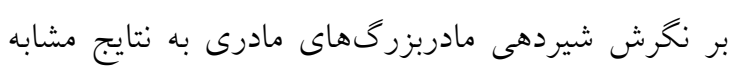

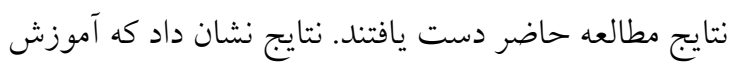
مادربزرخها در خروه مداخله در مقايسه با گروه كنترل

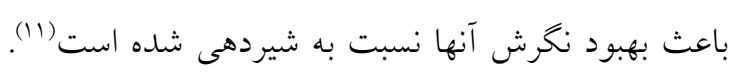

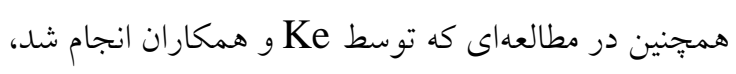

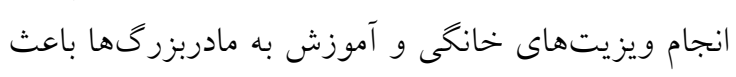

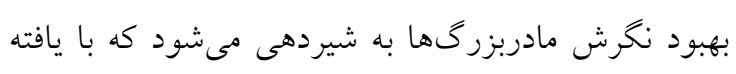
هاى مطالعه حاضر همخوانى دارد(r).

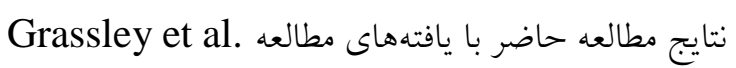

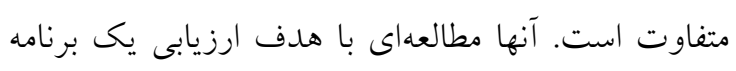

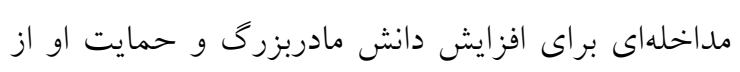

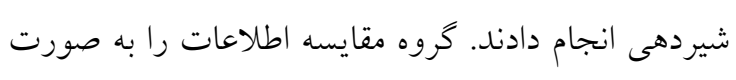

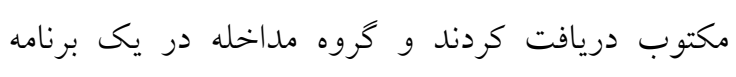
آموزشى تعاملى شركت كردند. نتايج نشان داد كه تفاوت درون

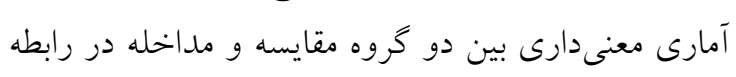
با نخرش شيردهى وجود نداشت. آنها علت معنى دار نشدن

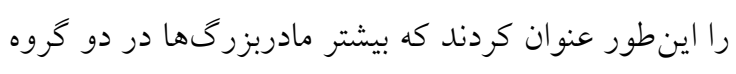

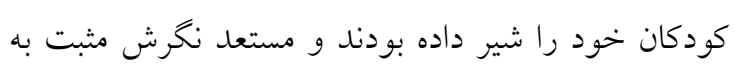

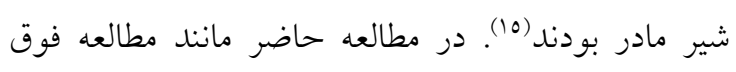

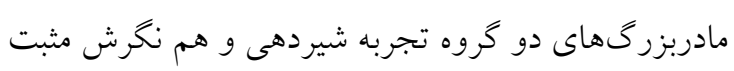

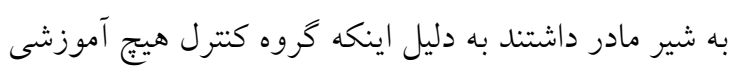
در مورد شير مادر دريافت نكردند اين مسئله قابل توجيه

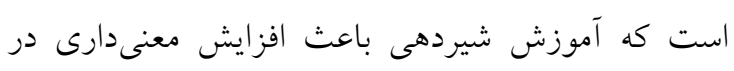

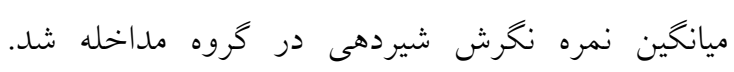

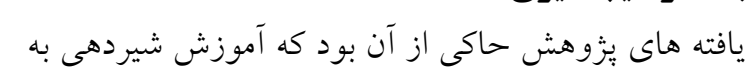

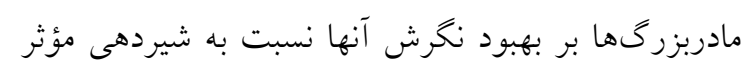

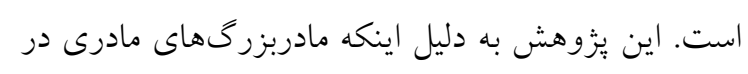

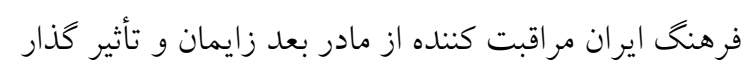

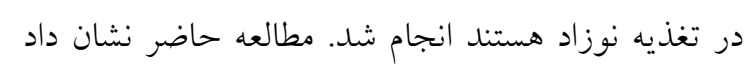

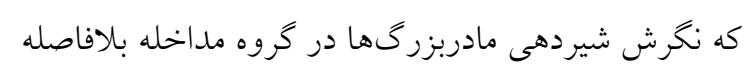

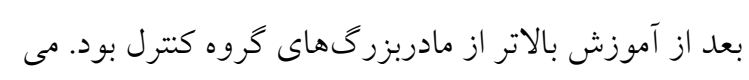

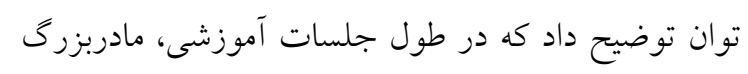

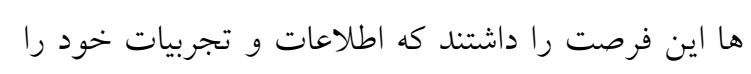

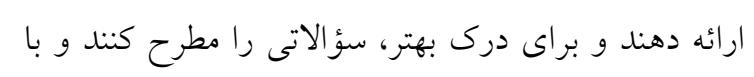

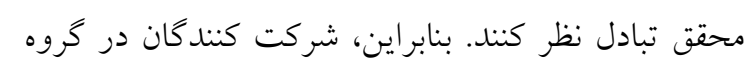

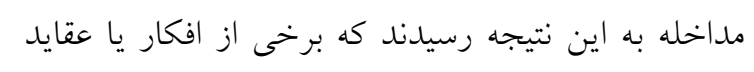

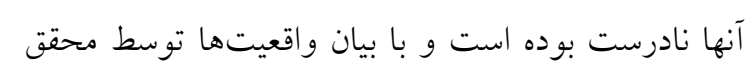

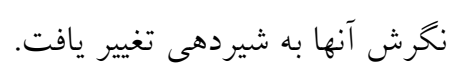

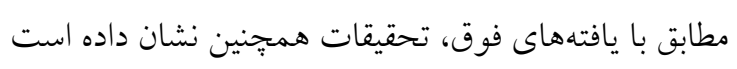

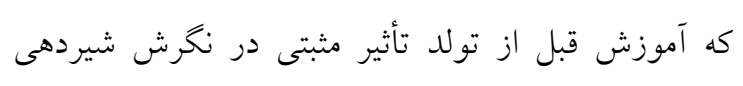

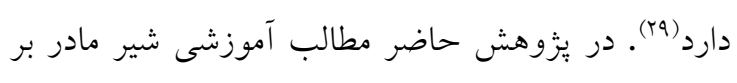

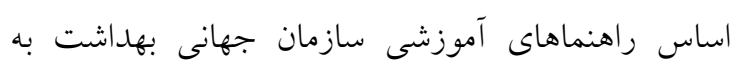

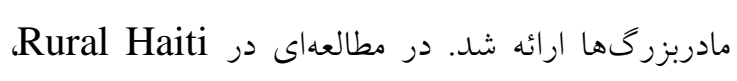

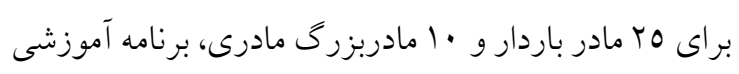

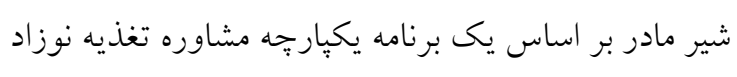
از سازمان جهانى بهداشت ( Infant and Young (Child Feeding Counseling كمى آموزشى (ياوريوينت) و بحث گروهى اجرا شد.

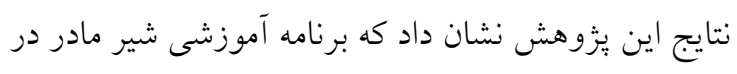

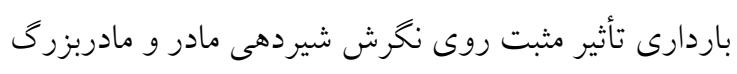
مادرى بلافاصله و يكى هفته بعد از مداخله دارد (r.). 
آموزش شيردهى مادربزرگها، فقط افزايش دانش و اطلاعات آنها نمىباشد بلكه تأثير آموزش بر نخرش آنها به آهريه شيرمادر است.

از محدوديتهاى مطالعه مىتوان به عدم تخصيص تصادفى و عدم بررسى نخرش مادربزرگها بعد از تولد

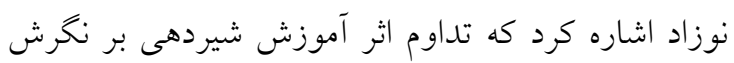

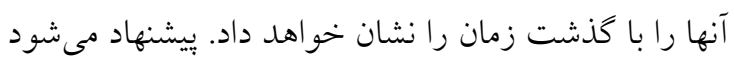
در جلسات آموزش شيردهى دوران يره ناتال نخرش مادر، مادربزرگ و ساير اعضاى خانواده مانند همسر و مادربزرى يدرى نيز نسبت به شير مادر مد نظر قرار كيرد. با تو جه به نتايج مطالعه حاضــر در كنار مطالعات انجام

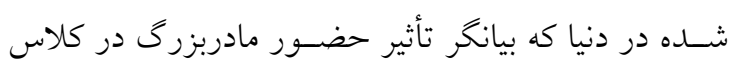
هاى آموزش شيردهى بر نخرش مثبت به شير مادر است،

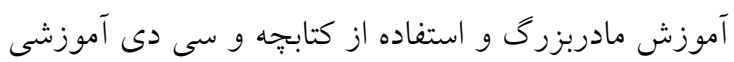
در منزل براى مادر و مادربزرگ، اصسـلاح نكرش منفى و باورهاى نادر ست شيردهى مادربزرگها نقش بسزايى در ترويج تغذيه با شير مادر دارد.

تعارض منافع: نويسندكان هيج گونه تعارض منافعى را كزارش نكردهاند.

\section{تقدير و تشكر}

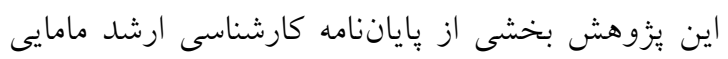

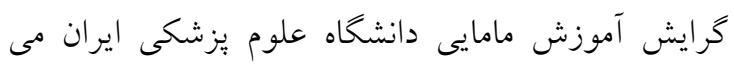
باشد. از تمام مادران و مادربزرگهايى كه در انجام اين دماني

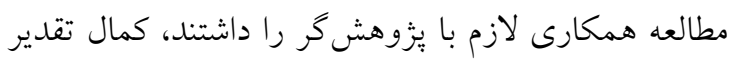

$$
\text { و تشكر را داريم. }
$$

مطالعات قبلى نشان مىدهد كه زمانى مادر در شيردهى موفق خواهد بود كه مادربزرى اذعان كند كه شيردهى مهم است، تصميم مادر را به شيردهى تصديق كند و مادر را تشويق كند كه بر مشكلات شيردهى غلبه كند(Tr). مادربزرگها اطلاعات اندكى در مورد شيردهى دارند، بعضى از آنها نخرش منفى در مورد شيردهى دارند يا داراى باورهاى غلطى در مورد شيردهى هستند بنابراين براى اصلاح اين باورها بهتر است مادربزرگها در كلاسهاى باى آموزش شيردهى شركت كنند. در مطالعه حاضر مطالب آب شيردهى، باورهاى نادرست شيردهى و اصلاح اين باورها به مادربزرگهاى گروه مداخله در جلسات آموزشى بيان شد و باعث افزايش ميانكين نمره نخرش به شير مادر در مارد

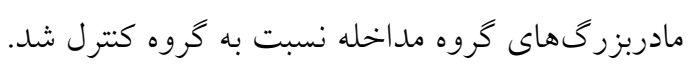

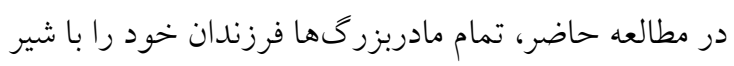
مادر تغذيه كرده بودند و تجربه شيردهى داشتند و با اجراى برنامه آموزشى، ميانخين نمره نخرش به شير مادر در گروه

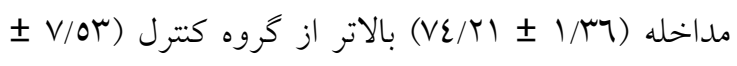
ץ|/7) بود. محققان در مطالعات خود به اين نتيجه رسيدند كه تجربه شيردهى مادربزرگهاى مادرى به عنوان يك مان

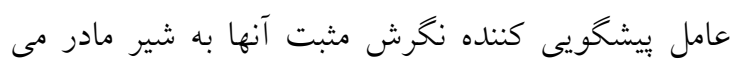

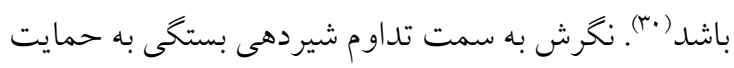

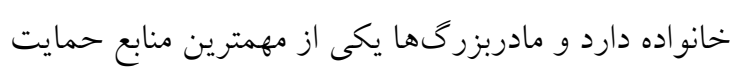

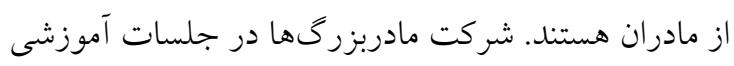
شير مادر در دوران برهناتال و بعد زايمان مىتواند باعث تشويق مادران به شيردهى شود و نخرشها و باورهاى غلط شيردهى آنها را اصلاح كند و نخرش مثبت به تغذيه با شير مادر و تداوم شيردهى تا ب سال را ايجاد كند. هدف از

\section{References}

1. Marandi A, Ezadin Zanjani N, Nilforoshan MA, Parsay S, and Khatami GR. Breastfeeding Updates for the pediatrician. Tehran: Breastfeeding Promotion Society.; 2014.

2. Twells LK, Midodzi WK, Ludlow V, Murphy-Goodridge J, Burrage L, Gill N, Halfyard B, Schiff R, Newhook LA. Assessing infant feeding attitudes of expectant women in a provincial population in Canada: validation of the Iowa Infant Feeding Attitude Scale. J Hum Lact. 2016;32(3):NP9-18.

3. Dennis CL. Breastfeeding initiation and duration: A 1990-2000 literature review. J Obstet, Gynecol Neonatal Nurs. 2002;31(1):12-32. 
4. LoCASCIO SP, Cho HW. The Effect of Attitudes Toward Breastfeeding in Public onBreastfeeding Rates and Duration: Results from South Korea. The Effect of Attitudes Toward Breastfeeding in Public onBreastfeeding Rates and Duration: Results from South Korea. 2017;4(4):208-45.

5. Bai Y, Middlestadt SE, Peng CY, Fly AD. Predictors of continuation of exclusive breastfeeding for the first six months of life. J Hum Lact. 2010 Feb;26(1):26-34.

6. de Jager E, Skouteris H, Broadbent J, Amir L, Mellor K. Psychosocial correlates of exclusive breastfeeding: a systematic review. Midwifery. 2013;29(5):506-18.

7. Chen S, Binns C, Liu Y, Maycock B, Zhao Y, Tang L. Attitudes towards breastfeeding-the Iowa infant feeding attitude scale in Chinese mothers living in China and Australia. Asia Pac J Clin Nutr. 2013;22(2):266-9.

8. Hamid SB, Chih HJ, Binns C. Predictors of Breastfeeding Intention in Malaysia. EnvironmentBehaviour Proceedings Journal. 2017;2(5):161-7.

9. Ratnayake HE, Rowel D. Prevalence of exclusive breastfeeding and barriers for its continuation up to six months in Kandy district, Sri Lanka. Int Breastfeed J. 2018;13(1):36.

10. Odom EC, Li R, Scanlon KS, Perrine CG, Grummer-Strawn L. Association of family and health care provider opinion on infant feeding with mother's breastfeeding decision. J Acad Nutr Diet. 2014 1;114(8):1203-7.

11. Bootsri W, Taneepanichskul S. Effectiveness of experiential learning with empowerment strategies and social support from grandmothers on breastfeeding among Thai adolescent mothers. Int Breastfeed J. 2017;12(1):37.

12. Bernie K. The factors influencing young mothers' infant feeding decisions: the views of healthcare professionals and voluntary workers on the role of the baby's maternal grandmother. Breastfeeding Medicine. 2014 1;9(3):161-5.

13. Cox KN, Giglia RC, Binns CW. The influence of infant feeding attitudes on breastfeeding duration: evidence from a cohort study in rural Western Australia. Int Breastfeed J. 2015;10(1):25.

14. Wojcicki JM, Gugig R, Tran C, Kathiravan S, Holbrook K, Heyman MB. Early exclusive breastfeeding and maternal attitudes towards infant feeding in a population of new mothers in San Francisco, California. Breastfeeding Medicine. 2010 1;5(1):9-15.

15. Grassley JS, Spencer BS, Law B. A grandmothers' tea: evaluation of a breastfeeding support intervention. J Perinatl Educ. 2012 1;21(2):80-9.

16. Negin J, Coffman J, Vizintin P, Raynes-Greenow C. The influence of grandmothers on breastfeeding rates: a systematic review. BMC Pregnancy Childbirth. 2016;16(1):91.

17. 1Reid J, Schmied V, Beale B. 'I only give advice if I am asked': examining the grandmother's potential to influence infant feeding decisions and parenting practices of new mothers. Women and Birth. 2010 1;23(2):74-80.

18. CDC. Strategy7-Access to Breastfeeding Education and Information 2017 [18 August 2017]. Available from: https://www.cdc.gov/breastfeeding/pdf/Strategy7-Access-BreastfeedingEducation.pdf.

19. Baghiani MM, Nadrian H, Rahaei Z. The effects of education on formula and bottle-feeding behaviors of nursing mothers based on PRECEDE model. Iranian Journal of Pediatrics. 2009;19(4):359-66. [Persian]

20. Kadima SN. Impact of a Formal Antenatal Breastfeeding Education Program on the Acceptance and Attitudes towards Exclusive Breastfeeding among Mothers and Grandmothers in Rural Haiti (Doctoral dissertation, Duke University); 2018.

21. Ke J, Ouyang YQ, Redding SR. Family-centered breastfeeding education to promote primiparas' exclusive breastfeeding in China. J Hum Lact. 2018;34(2):365-78.

22. Grassley J, Eschiti V. Grandmother breastfeeding support: what do mothers need and want? Birth. 2008;35(4):329-35.

23. Olang B, Heidarzadeh A, Strandvik B, Yngve A. Reasons given by mothers for discontinuing breastfeeding in Iran. Int Breastfeed J. 2012;7(1):7.

24. Barakati H, Saadvandian S, and Motlagh ME. Breastfeeding; An effective cost investment. Tehran: Mandegar Andisheh; 2017

25. Esfahani MM, oladi B, Bahrami M PS. Educational Collection of Breastfeeding Promotion. Tehran: UNICEF; 2009. 
26. Ministry of Health and Medical Education. Guidebook for monitoring baby friendly hospitals. Tehran: Andisheh e Mandegar; 2015.

27. Faridvand F, Mirghafourvand M, Mohammad-Alizadeh-Charandabi S, Malakouti J. Breastfeeding performance in Iranian women. Int J Nurs Pract. 2018;24(4):e12659.

28. Mora AD, Russell DW, Dungy CI, Losch M, Dusdieker L. The Iowa Infant Feeding Attitude Scale: Analysis of Reliability and Validity 1. J Appl Soc Psychol. 1999;29(11):2362-80.

29. Arsin AA, Sirajuddin S, Syafar M. The effect of education lactation on breastfeeding behavior infant 0-6 months in Kendari Indonesia. Public Health of Indonesia. 2016 30;2(2):100-11.

30. Bartle NC, Harvey K. Explaining infant feeding: The role of previous personal and vicarious experience on attitudes, subjective norms, self-efficacy, and breastfeeding outcomes. Br J Health Psychol. 2017;22(4):763-85. 